\title{
EJNSO
}

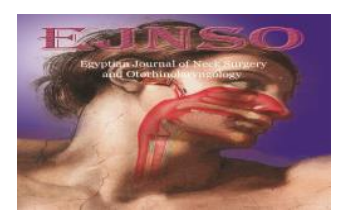

\section{Symptomatic treatment versus symptomatic treatment with antibiotics for children with acute otitis media: A randomized clinical trial}

\author{
Hamza El-shafaai Ahmed ${ }^{1}$, Ahmed AbdelAleem AbdelWahab ${ }^{1}$, Ahmed Gamal \\ Abdel Hameeed ${ }^{2}$.
}

1- Otorhinolaryngology, Faculty of Medicine, Assiut University, Egypt.

2- Otorhinolaryngology, Students Hospital, Assiut University, Egypt.

\begin{abstract}
:
Introduction: Acute otitis media (AOM) is one of the most common infections affecting children. Around $60 \%$ of children have had at least one episode of AOM by four years. It is also one of the main reasons for antibiotic prescription in children. Many studies have shown that the majority of cases of pediatric AOM resolve spontaneously without antibiotics. Undue use of antibiotics is considered one of the leading causes of antibiotic resistance. Besides the added cost, antibiotics also have their inherited risk of side effects, including vomiting, diarrhea, and rash.

Methods: A randomized clinical trial on 102 children-normal kids- aged 2-12 years with AOM to compare the results of using symptomatic treatment only with those using both symptomatic treatment plus antibiotic.

Results: On the 3rd day of treatment, there was statistically significant better control of pain and fever in the antibiotic group. There was no statistically significant difference by the 8th day of treatment. Tympanometric findings by the end of the 3rd week were very much similar in both groups. No complications of AOM or side effects of drugs under study were reported.

Conclusion: Immediate antibiotic use to treat children with AOM who are otherwise normal may provide one or 2 days of earlier control of ear pain and fever in some children. A few days later -by the 8th day- the effect of symptomatic treatment and symptomatic treatment plus antibiotic was similar with no increased incidence of complications.
\end{abstract}

Keywords: AOM; conservative treatment; Antibiotics; Pediatrics; otitis media

\section{Introduction}

Acute otitis media (AOM) is one of the most common infections affecting children. ${ }^{1}$ It is estimated that at least $60 \%$ of children have had at least one episode of AOM by the age of 4 years. ${ }^{2}$

The incidence increases to $75 \%$ by the age of $5 .{ }^{3}$ Recurrence is also common to the extent that one-third of affected

children have two or more episodes in the first three years of life.

AOM has its direct and indirect costs. Diseased children need at least one doctor visit with a prescription of medications. Lost days of work for one parent add to the total cost of the problem. The quality of life of both 
children and their family during this illness is thus negatively affected. ${ }^{4}$

Data from high-level evidence studies show that immediate usage of antibiotics may decrease the duration of symptoms. ${ }^{5-6}$ This shorter course of the disease is at the expense of increased antibiotic resistance risk. Most international treatment guidelines for pediatric AOM recommend watchful waiting with symptomatic treatment for children older than two years who have a low risk of complications. ${ }^{7-8}$

This study aimed to compare symptomatic treatment with symptomatic treatment plus antibiotics for children with AOM aged 2-12 years who are not at a high risk of complications.

\section{Patients and Methods:}

This clinical trial was conducted at the ENT outpatient clinic, Assiut University Hospital, from December 2017 till January 2019 on 102 children Approval from the local Medical Ethical Committee and consent from one parent of the participant children were obtained before joining the study.

The study included all children attending the clinic with AOM in the catarrhal or suppurative stage between 2-12 years. Patients received antibiotic treatment in the previous two weeks, and patients with a concurrent infection requiring antibiotics were excluded. Patients with a systemic illness like Diabetes and patients with diarrhea were excluded. Patients with marked bulging or impending rupture of the TM, patients with otorrhea due to recent or pre-existing perforation, and patients with complicated AOM (as facial palsy) were also excluded. Patients refused to share in this study, and patients who did not comply with the study's rules or did not come for the planned follow-up were excluded.
A detailed history was taken, and all children were subjected to full general and ENT examination, including endoscopic examination of the TM using a 0-degree $(2.7$ or $4 \mathrm{~mm})$ endoscope. Diagnosis of AOM was done based on the 2008 clinical guidelines of the National Institute of Health \& Care Excellence, Clinical Knowledge Summaries (NICE, CKS) in the UK. ${ }^{9}$

\section{1-History}

General symptoms (Non-specific symptoms, e.g., fever, irritability, crying, poor feeding)

$$
\text { Local symptoms (Earache, }
$$
pulling/tugging of ear)

\section{2-Examination}

\section{General examination (Fever) \\ Local otologic examination}

1- Red, yellow, or cloudy TM, bulging TM, air-fluid level.

2- Perforation and/or discharge in the ear canal.

Patients were also subjected to full blood count, blood sugar measurement, and tympanometry to confirm the presence of middle ear (ME) fluid. Lateral view soft tissue X-ray to the nasopharynx was obtained if adenoid enlargement was suspected.

Parameters used to judge the response to treatment and to compare the 2 strategies of treatment were:

\section{- Body temperature}

Body temperature measured and classified. ${ }^{10}$

- Otalgia using Wong-Baker Faces scale.

- Otoscopic examination of the external auditory canal \&TM

The external auditory canal was cleaned of wax and debris and excluded as a cause of ear pain. The TM was examined to confirm the diagnosis, detect cases with impending rupture, exclude perforation, monitor the response to treatment, and detect cases of treatment failure. 
- Tympanometry: Was done before treatment and at the end of the $3^{\text {rd }}$ week of treatment for all children included in the study. The obtained tympanograms were distinguished into four types as classified by Fiellau-Nikolajsen 1977. ${ }^{12}$

Patients were randomly allocated into 2 groups (A and B). Patients in group A were treated using oral acetaminophen at a dose of $30-60 \mathrm{mg} / \mathrm{kg} / \mathrm{day}$ in $3-4$ divided doses. Patients in group B were treated using the same dose of oral acetaminophen with oral amoxicillin/ clavulanic acid $(642.9 \mathrm{mg} / 5 \mathrm{ml})$ at doses of $90 \mathrm{mg} / \mathrm{kg} /$ day of amoxicillin component in 2 divided doses for 5 days(maximum 2000mg/day). Cefdinir at a dose of $14 \mathrm{mg} / \mathrm{kg} / \mathrm{day}$ in 2 divided doses (maximum 600mg) was used for patients with penicillin allergy or intolerance.

Patients were asked to come back for a follow-up in the outpatient clinic of Assiut University Hospital on the 3rd day (early post-treatment visit), 8th day (late post-treatment visit), and at the end of the 3rd week (Tympanometric visit) of treatment. Patients were also asked to come immediately when they noticed an increase in body temperature, persistence or worsening of pain or appearance of new symptoms (like otorrhea), or appearance of complications from AOM or the drugs used. Patients and their caregivers were stressed not to take any other medications on their own and stop acetaminophen 8 hours before planned follow-up visits.

At the 3rd and 8th days of treatment, temperature and pain degree were recorded and compared in both groups. Tympanometry was done at the end of 3rd week for each case.

During follow-up, fever above 39.5 degrees, persistent pain $>6$ on WongBaker Faces Scale beyond the 3rd day, impending rupture or rupture of the TM and appearance of complications were considered a treatment failure. Intramuscular ceftriaxone at a $50 \mathrm{mg} / \mathrm{kg} /$ day dose was given once daily for 3 days for these cases after performing sensitivity test. For failed patients in group (A) we considered their records when shifting to ceftriaxone, their 8thday data when we compared the results of the 2 groups.

Data at the time of myringotomy was considered their 8th-day data.

\section{Data analysis:}

Data entry and data analysis were done using SPSS (Statistical Package for Social Science) version 22, IBM, Chicago, IL. Data were presented as number, percentage, mean, and standard deviation. P-value was considered statistically significant when $\mathrm{P}<0.05$.

\section{Results:}

A total of 102 children with AOM (51 for each group) were enrolled in this study. These patients' age ranged between 2-11 years with a mean of 3.85 \pm 1.9 years. There were 57 males and 45 females. The left side was affected in 58 patients and the right in 44 .

Table (1) showed the pre-treatment data of both groups. There was no significant difference between the two groups regarding demographic data, side of AOM, pre-treatment symptom severity, or co-morbidities.

Table (2) compared the pre-treatment body temperature with early and late post-treatment temperature for patients in both groups. There was statistically highly significant improvement in fever at both early and late visits compared with pre-treatment visits in both groups. When both groups were compared, there was statistically significant better control of fever in group B than in group $A$ in early post medication visit ( $p$ 
$=0.019)$. However, by the 8th day, no statistically significant difference in fever control was present between the two groups $(\mathrm{p}=0.503)$.

Table (3) compared mean \& median pain scores at the pre-treatment, early, and late post-treatment visits in both groups. There was a highly significant reduction in the mean and median pain scores in both groups at the early and late post-treatment visits compared with the pre-treatment one. The antibiotic group (group B) showed statistically significant lower pain scores than group $\mathrm{A}$ in the early post-treatment visit $(\mathrm{p}=0.007)$ with no statistically significant difference at late posttreatment visit $(\mathrm{p}=0.649)$.

Table (4) compared the number of cases with flat tympanogram by the end of the 3rd week and the number of patients with treatment failure in both groups. There were 4 cases with treatment failure; 3 cases were in group $A$ and the 4th case in $B$ with no statistically significant difference between both studied groups. The tympanometric findings in both groups by the end of the 3rd week were almost similar.

Table (5) searched for something in common in the 4 cases with treatment failure. The two findings in common were bulged TM and a high pain score ( $\geq 8$ on Wong-Baker Scale) at the time of diagnosis. The age and sex of the patient, degree of fever at the time of diagnosis, presence of adenoids, anemia, and antibiotic use did not seem to affect treatment failure.

There were no cranial or intracranial complications reported from any patient. Also, patients reported no significant side effects of the used medications. 
Table (1): Shows pre-treatment data of all children enrolled in our study

\begin{tabular}{|c|c|c|c|}
\hline & Total no. (102) & Group A (51) & Group B (51) \\
\hline \multicolumn{4}{|l|}{ Personal data: } \\
\hline \multicolumn{4}{|l|}{ Sex: } \\
\hline Male & $57 \quad(55.9 \%)$ & $30 \quad(58.8 \%)$ & $27 \quad(52.9 \%)$ \\
\hline Female & $45 \quad(44.1 \%)$ & $21 \quad(41.2 \%)$ & $24 \quad(47.1 \%)$ \\
\hline \multicolumn{4}{|c|}{ Age: (years) } \\
\hline Mean \pm SD & $3.85 \pm 1.82$ & $3.68 \pm 2.69$ & $3.87 \pm 2.91$ \\
\hline Range & $2.0-11.0$ & $2.0-11.0$ & $2.5-11.0$ \\
\hline \multicolumn{4}{|l|}{ Clinical picture: } \\
\hline \multicolumn{4}{|l|}{ Side of AOM: } \\
\hline Right & $47(46.1 \%)$ & $25 \quad(49.0 \%)$ & $23 \quad(45.1 \%)$ \\
\hline Left & $55 \quad(54.9 \%)$ & $26 \quad(51.0 \%)$ & $28 \quad(54.9 \%)$ \\
\hline \multicolumn{4}{|l|}{ Grade of fever } \\
\hline Low & $48 \quad(47.1 \%)$ & $25 \quad(49.0 \%)$ & $23 \quad(45.1 \%)$ \\
\hline Moderate & $39(38.2 \%)$ & $19(37.3 \%)$ & $20 \quad(39.2 \%)$ \\
\hline High & $15(14.7 \%)$ & $7(13.7 \%)$ & $8(15.7 \%)$ \\
\hline \multicolumn{4}{|c|}{ Ear pain: on (Wong-Baker Faces scale) } \\
\hline Mean \pm SD & $7.73 \pm 0.89$ & $7.45 \pm 1.06$ & $7.67 \pm 0.49$ \\
\hline Range & $6.0-10.0$ & $8.0(6.0-10.0)$ & $8.0(6.0-10.0)$ \\
\hline \multicolumn{4}{|l|}{ TM examination: } \\
\hline Moderate congestion & $21 \quad(20.6 \%)$ & $9 \quad(17.6 \%)$ & $12(23.5 \%)$ \\
\hline Diffuse congestion & $71 \quad(69.6 \%)$ & $36(70.6 \%)$ & $35 \quad(68.6 \%)$ \\
\hline Bulged TM & $10 \quad(9.8 \%)$ & $6 \quad(11.8 \%)$ & $4 \quad(7.8 \%)$ \\
\hline \multicolumn{4}{|l|}{ Complete blood picture: } \\
\hline Anemia $(\mathrm{Hb}<10.5)$ & $15(14.7 \%)$ & $9 \quad(\mathbf{1 7 . 6 \%})$ & $6(11.7 \%)$ \\
\hline$\frac{\text { Leucocytosis }}{\left.\mathrm{x} 10^{3} / \mu \mathrm{L}\right)}$ above 11 & $10(9 \%)$ & $4(7.8 \%)$ & $6(11.7 \%)$ \\
\hline \multicolumn{4}{|l|}{ Associated conditions : } \\
\hline Common cold & $83 \quad(81.4 \%)$ & $39(76.5 \%)$ & $44 \quad(86.3 \%)$ \\
\hline Adenoids & $23 \quad(22.5 \%)$ & $12(23.5 \%)$ & $11(21.6 \%)$ \\
\hline penicillin allergy & $2(1.9 \%)$ & $1(1.9 \%)$ & $1 \quad(1.9 \%)$ \\
\hline
\end{tabular}

Table (2): Comparison between the temperatures at the pre-treatment, early and late posttreatment visits in both groups

\begin{tabular}{|c|c|c|c|c|c|c|c|c|c|}
\hline \multirow[t]{2}{*}{ Group } & \multirow[t]{2}{*}{ Temperature } & \multicolumn{2}{|c|}{\begin{tabular}{|c} 
Premedication \\
visit \\
$(\mathbf{n}=\mathbf{5 1})$
\end{tabular}} & \multicolumn{2}{|c|}{$\begin{array}{c}\text { Early post- } \\
\text { treatment } \\
\text { visit }(n=51) \\
\end{array}$} & \multirow[t]{2}{*}{ P-value ${ }^{1}$} & \multicolumn{2}{|c|}{$\begin{array}{c}\text { Late post- } \\
\text { treatment visit } \\
(n=51)\end{array}$} & \multirow[t]{2}{*}{ P-value $^{2}$} \\
\hline & & No. & $\%$ & No & $\%$ & & No & $\%$ & \\
\hline \multirow{4}{*}{ Group A } & Normal & 0 & 0.0 & 24 & 47.1 & \multirow{4}{*}{$0.000 *$} & 48 & 94.1 & \multirow{4}{*}{0.000} \\
\hline & \begin{tabular}{|l|} 
Low grade \\
\end{tabular} & 25 & 49 & 17 & 33.3 & & 1 & 2.0 & \\
\hline & Moderate & 19 & 37.3 & 8 & 15.7 & & 2 & 3.9 & \\
\hline & High grade & 7 & 13.7 & 2 & 3.9 & & 0 & 0.0 & \\
\hline \multirow{4}{*}{ Group B } & Normal & 0 & 0.0 & 39 & 76.5 & \multirow{4}{*}{$0.000^{*}$} & 50 & 98 & \multirow{4}{*}{$0.000 *$} \\
\hline & \begin{tabular}{|l|} 
Low grade \\
\end{tabular} & 23 & 45.1 & 9 & 17.6 & & 0 & 0.0 & \\
\hline & Moderate & 20 & 39.2 & 2 & 3.9 & & 1 & 2.0 & \\
\hline & \begin{tabular}{|l|} 
High grade \\
\end{tabular} & 8 & 15.7 & 1 & 2.0 & & 0 & 0.0 & \\
\hline P-value ${ }^{3}$ & & & & \multicolumn{2}{|c|}{$0.019 *$} & & \multicolumn{2}{|c|}{0.503} & \\
\hline
\end{tabular}

1: Comparison between pre-medication and early post-treatment visit (Chi-square test)

2: Comparison between pre-medication and late post-treatment visit (Chi-square test)

3: Comparison between group A and group B (Chi-square test) 
Table (3): Comparison between the mean \& median pain scores at the pre-treatment, early, and late post-treatment visits in both groups

\begin{tabular}{|c|c|c|c|c|c|c|}
\hline Groups & Ear pain & $\begin{array}{c}\text { Pre-treatment } \\
\text { visit } \\
(n=51)\end{array}$ & $\begin{array}{c}\text { Early post- } \\
\text { treatment visit } \\
(n=51)\end{array}$ & P-value ${ }^{1}$ & $\begin{array}{c}\text { late post- } \\
\text { treatment visit } \\
(n=51)\end{array}$ & P-value ${ }^{2}$ \\
\hline \multirow{2}{*}{ Group A } & Mean \pm SD & $7.45 \pm 1.06$ & $2.39 \pm 2.99$ & \multirow{2}{*}{$0.000 *$} & $0.12 \pm 0.48$ & \multirow{2}{*}{$0.000^{*}$} \\
\hline & Median (Range) & $8.0(6.0-10)$ & $2.0(0.0-10.0)$ & & $0.0(0.0-2.0)$ & \\
\hline \multirow{2}{*}{ Group B } & Mean \pm SD & $7.67 \pm 0.49$ & $1.33 \pm 2.67$ & \multirow{2}{*}{$0.000 *$} & $0.08 \pm 0.39$ & \multirow{2}{*}{$0.000 *$} \\
\hline & Median (Range) & $8.0(6.0-10.0)$ & $0.0(0.0-8.0)$ & & $0.0(0.0-2.0)$ & \\
\hline P-value ${ }^{3}$ & & & $0.007 *$ & & 0.649 & \\
\hline
\end{tabular}

1: Comparison between pre-medication and early post-treatment visit (Wilcoxon Signed Rank test)

2: Comparison between pre-medication and late post-treatment visit (Wilcoxon Signed Rank test)

3: Comparison between group A and group B (Mann-Whitney test)

Table (4) between the 2 groups in terms of treatment failures and residual MEE

\begin{tabular}{|l|c|c|c|}
\hline \multicolumn{1}{|c|}{ Point of comparison } & $\begin{array}{c}\text { Group A } \\
(\mathbf{n = 5 1})\end{array}$ & $\begin{array}{c}\text { Group B } \\
(\mathbf{n = 5 1})\end{array}$ & P-value \\
\hline Treatment failure & 3 & 1 & $\mathbf{P}^{1}=0.617$ \\
\hline Flat Tympanogram at 3 ${ }^{\text {rd }}$ week & 20 & 16 & $\mathbf{P}^{2}=0.407$ \\
\hline
\end{tabular}

1: Comparison between treatment failure cases in both groups (Fisher Exact test)

2: Comparison between post-AOM ME effusion in both groups (Chi-square test)

Table (5) Summarizing data of children with treatment failure

\begin{tabular}{|c|c|c|c|c|c|c|c|c|c|c|}
\hline $\begin{array}{c}\text { Case } \\
\text { No. }\end{array}$ & Group & Sex & Age & Adenoids & $\begin{array}{c}\text { Common } \\
\text { cold }\end{array}$ & Anemia & Leukocytosis & Ear pain & Fever & TM \\
\hline 1 & A & Female & 8 & Yes & Yes & No & Yes & 8 & Moderate & Bulged \\
\hline 2 & A & Female & 5 & Yes & Yes & No & Yes & 8 & low & Bulged \\
\hline 3 & A & Female & 7 & No & No & Yes & No & 8 & Moderate & Bulged \\
\hline 4 & B & Male & 10 & No & Yes & Yes & Yes & 8 & High & Bulged \\
\hline
\end{tabular}

\section{Discussion:}

The proper treatment of children with AOM has been a matter of extensive research and systematic reviews. According to these studies' results, the guidelines released from various academies concerned with this topic are being modified now and then. The main point of controversy is whether antibiotics have a clinical significance that compensates for the added cost, potential side effects, and the risk of bacterial resistance.

In our study, we compared treating our patients with acetaminophen with or without Amoxicillin/ Clavulanic acid.

Our patients' age ranged from 2 to 11 years, with a mean age between 3.5-4 years. Although the peak incidence of AOM worldwide is definitely at a lower age group, we believe that a significant sector of the younger patients with AOM attended the pediatric and family clinics, so we missed them.

There was a statistically significant improvement in both pain and fever with acetaminophen whether or not it was taken with the antibiotic. Using Amoxicillin/ Clavulanic acid with acetaminophen resulted in better control of pain and fever at the 3rd day than acetaminophen alone. The results however- were much similar by the 8th day. In other words, there was earlier control of pain and fever with antibiotic use by 2 or 3 days (Table 2 and 3). Our patients had to stop acetaminophen 8 hours before measuring the body temperature and scoring the pain for validating the measurement and comparison. Stopping acetaminophen 
wouldn't be necessary for actual practice. Such a difference in the early days of treatment might pass unnoticed, so we believe it is rather a statistical difference that does not necessarily echoes a clinical significance.

We can conclude from Tables 2 and 3 that the fever and pain results were very much similar and went parallel to each other in both groups at each time of evaluation. This is quite logical because both pain and fever directly result from the ongoing inflammatory condition and the released inflammatory products. The presence of serous or muco-pus exudates in the closed ME cavity. So one parameter mirrors the other, and one can use any or both of them to monitor the response to treatment of AOM.

Damoiseaux and Rovers in their systematic review in 2011 found that without antibiotic, AOM resolves within 24 hours in about $60 \%$ of cases and within 3 days in about $80 \%$ of cases. With antibiotic usage, the pain has been reduced at the 2 nd to 7 th day at the expense of increasing the risk of vomiting, diarrhea, and rashes besides the antibiotics' expenses and the increased chance for antibiotic resistance. They also found that although immediate use of antibiotics may provide a short-term reduction in some AOM related symptoms, it increased the risk of rashes and diarrhea compared with delayed-onset antibiotic use. They concluded that symptomatic treatment with a back-up antibiotic in treatment failure cases after 48 hours or so might be a good alternative to immediate use of antibiotics. Their study also concluded that analgesics and local treatment are beneficial in controlling ear pain. ${ }^{13}$

Venekamp et al. in their systematic review about antibiotics for otitis media in children published in 2015 also found $60 \%$ improvement of AOM symptoms after 24 hours, whether with the use of antibiotics or placebo. They also found $5 \%$ fewer children with pain with antibiotics than placebo at three days. The difference increased to $6 \%$ and 14 $\%$ fewer children with pain with antibiotic than placebo on the 7 th and 12th day. On the other hand, their systematic review also found a $38 \%$ relative increase in the risk of adverse effects related to antibiotic use like diarrhea and vomiting. ${ }^{14}$

We had 4 cases of treatment failure in this study (Table 4). Three cases were in group A and one case in group B, with no significant difference between the 2 groups. The manifestations of treatment failure were persistent pain out of control and fever. A close look to Table (5) to pick up any possible finding that might explain or predict treatment failure revealed that all these patients had bulged TM at presentation with high pain score ( 8 on the pain visual analog scale). This might point to the relatively severe form of infection and/or to a relatively delayed presentation of these patients with the increasing chance of secondary bacterial infection.

The severity of AOM has been long considered an important factor when considering the early antibiotic prescription. ${ }^{15-21}$

The presence of leucocytosis in 3 out of these 4 patients may support the explanation of secondary bacterial infection as a cause of failure. Nibhanipudi et al. have used the WBC count in the peripheral blood film as a parameter for the need for antibiotic utilization in pediatric patients with AOM. Using the WBC $>15,000$ as the cut-off value for giving antibiotics for these patients while offering close observation for patients with lower WBC values, they found it very helpful to obtain good results with avoiding unnecessary antibiotic usage. ${ }^{22}$

Table (4) also showed no statistically significant difference between the 2 
groups in terms of the number of patients left with OME by the end of the 3rd week $(p=0.4)$. Venekamp et al. in their study found $18 \%$ relative reduction in abnormal tympanometric findings at 2-4 weeks. This incidence decreased to $12 \%$ at 6 th -8 th week. However, at three months, there was no statistically significant reduction in the risk of abnormal tympanometric findings between the antibiotic and placebo. ${ }^{14}$ Other studies concluded the same longterm outcome relative to OME after AOM with or without antibiotic treatment. Ruohola et al. in their Finish study published 2017, found no significantly different effect of immediate use of antibiotics on the resolution of post-AOM MEE in young children. The main reason for persistent MEE -they found- was the subsequent recurrences of AOM and not the way of their treatment. ${ }^{23}$

A close look to most studies that reported some link between antibiotic use and lower incidence of MEE after AOM quickly reveals that their time of evaluation and judgment of the presence of MEE was early. ${ }^{24-26}$

Also, needless to say, that our patients were having AOM before perforation while they were otherwise normal, so in patients with otorrhea, complications, and medical co-morbidities, etc., other roles might be more appropriate.

\section{Conclusion:}

Immediate antibiotic use to treat children with AOM who are otherwise normal may provide one or 2 days of earlier control of ear pain and fever in some children. A few days later -by the 8th day- the effect of symptomatic treatment and symptomatic treatment plus antibiotic was similar with no increased incidence of complications.

\section{Limitation of the work:}

It is crucial here to announce that the number of patients who failed medical treatment in our study and the number of the cases in the study itself relative to the high prevalence of the problem of AOM both are relatively too small to get solid conclusions from them.

\section{Reference:}

1. Schilder AG, Chonmaitree T, Cripps AW, Rosenfeld RM, Casselbrant ML, Haggard MP, et al. Otitis media. Nature Reviews Disease Primers. 2016;2(1):118.

2. Kaur R, Morris M, Pichichero ME. Epidemiology of acute otitis media in the postpneumococcal conjugate vaccine era. Pediatrics. 2017;140(3).

3. Organization WH. Antimicrobial resistance: global report on surveillance: World Health Organization; 2014.

4. Vernacchio L, Vezina RM, Mitchell AA. Management of acute otitis media by primary care physicians: trends since the release of the 2004 American Academy of Pediatrics/American Academy of Family Physicians clinical practice guideline. Pediatrics. 2007;120(2):281-7.

5. Kenealy T, Arroll B. Antibiotics for the common cold and acute purulent rhinitis. Cochrane Database of Systematic Reviews. 2013(6).

6. Rodrigues AT, Roque F, Falcão A, Figueiras A, Herdeiro MT. Understanding physician antibiotic prescribing behaviour: a systematic review of qualitative studies. International journal of antimicrobial agents. 2013;41(3):203-12.

7. Gualano MR, Gili R, Scaioli G, Bert F, Siliquini R. General population's knowledge and attitudes about antibiotics: a systematic review and meta-analysis. Pharmacoepidemiology and drug safety. 2015; 24(1):2-10.

8. Coxeter PD, Del Mar C, Hoffmann TC. Parents' expectations and experiences of antibiotics for acute respiratory infections in primary care. The Annals of Family Medicine. 2017;15(2):149-54.

9. NICE CfCPa. Respiratory tract infections-antibiotic prescribing: prescribing of antibiotics for self-limiting respiratory tract infections in adults and children in primary care. 2008. 
10. Springhouse. Fever in handbook of signs \& symptoms. 3rd edition Lippincott Williams \& Wilkins; 2006. Available at: http://www.wrongdiagnosis.com/m/mon onucleosis/bookdiseases-5a.htm.

11. Chambers CT, Giesbrecht K, Craig KD, Bennett SM, Huntsman E. A comparison of faces scales for the measurement of pediatric pain: children's and parents' ratings. Pain. 1999;83(1):25-35.

12. Fiellau-Nikolajsen M, Lous J, Pedersen $\mathrm{SV}$, Schousboe H. Tympanometry in Three-Year-Old Children I. A Regional Prevalence Study on the Distribution of Tympanometric Results in a Nonselected Population of 3-Year-Old Children. Scandinavian audiology. 1977;6(4):199-204.

13. Damoiseaux RA, Rovers MM. AOM in children. BMJ clinical evidence. 2011;2011.

14. Venekamp RP, Sanders SL, Glasziou PP, Del Mar CB, Rovers MM. Antibiotics for acute otitis media in children. Cochrane database of systematic reviews. 2015(6).

15. Palma S, Rosafio C, Del Giovane C, Patianna VD, Lucaccioni L, Genovese E, et al. The impact of the Italian guidelines on antibiotic prescription practices for acute otitis media in a paediatric emergency setting. Italian journal of pediatrics. 2015;41(1):37.

16. Levy C, Pereira M, Guedj R, Abt-Nord C, Gelbert NB, Cohen R, et al. Impact of 2011 French guidelines on antibiotic prescription for acute otitis media in infants. Medecine et maladies infectieuses. 2014;44(3):102-6.

17. McGrath LJ, Becker-Dreps S, Pate V, Brookhart MA. Trends in antibiotic treatment of acute otitis media and treatment failure in children, 2000-2011. PloS one. 2013;8(12):e81210.

18. Coco A, Vernacchio L, Horst M, Anderson A. Management of acute otitis media after publication of the 2004 AAP and AAFP clinical practice guideline. Pediatrics. 2010; 125(2):214-20.
19. Thompson P, Gilbert R, Long P, Saxena S, Sharland M, Wong I. Has UK guidance affected general practitioner antibiotic prescribing for otitis media in children? Journal of public health. 2008;30(4):479-86.

20.20. Ríos L, Mallafré M, GonzálezHidalgo R, Collado A, Carbonell J, Colomés L. Aplicación de una pauta terapéutica revisada de otitis media en una consulta pediátrica. Revista de Calidad Asistencial. 2003; 18(1):5-8.

21.21. Lieberthal AS, Carroll AE, Chonmaitree T, Ganiats TG, Hoberman A, Jackson MA, et al. The diagnosis and management of acute otitis media. Pediatrics. 2013;131(3):e964-e99.

22.K V Nibhanipudi GWH, A Jain. The Utility Of Peripheral White Blood Cell Count In Cases Of Acute Otitis Media In Children Between 2 Years And 17 Years Of Age. The Internet Journal of Otorhinolaryngology. 2016; Volume 18 Number 1(DOI: 10.5580/IJORL.38086).

23. Ruohola A, Laine MK, Tähtinen PA. Effect of antimicrobial treatment on the resolution of middle-ear effusion after acute otitis media. Journal of the Pediatric Infectious Diseases Society. 2017;7(1):64-70.

24. Hoberman A, Paradise JL, Rockette HE, Shaikh N, Wald ER, Kearney DH, et al. treatment of acute otitis media in children under 2 years of age. New England Journal of Medicine. 2011;364(2):105-15.

25. Kaleida PH, Blatter MM, Reisinger KS, Wald ER, Casselbrant ML, Bluestone $\mathrm{CD}$, et al. Amoxicillin or myringotomy or both for acute otitis media: results of a randomized clinical trial. Pediatrics. 1991;87(4):466-74.

26. Tapiainen $\mathrm{T}$, Kujala $\mathrm{T}$, Renko $\mathrm{M}$, Koivunen P, Kontiokari T, Kristo A, et al. Effect of antimicrobial treatment of acute otitis media on the daily disappearance of middle ear effusion: a placebo-controlled trial. JAMA pediatrics. 2014;168(7):635-41. 